\title{
Inhaltsverzeichnis
}

Danksagung . . . . . . . . . . . . . . . . . . . . . . . . . . . . $\mathrm{V}$

Abkürzungsverzeichnis . . . . . . . . . . . . . . . . . . . . . . . . IX

Teil I: Text

Einleitung . . . . . . . . . . . . . . . . . . . . . . . . . . . . . 3

I Forschungsgeschichte . . . . . . . . . . . . . . . . . . . . . . . 6

I.I Quellenkritik . . . . . . . . . . . . . . . . . . . . . . . 20

2 Geographische Lage und klimatische Verhältnisse des Untersuchungsgebietes . . . . . 25

3 Die bronzezeitlichen Fundplätze . . . . . . . . . . . . . . . . . . . . 28

3.I Die Chronologie der Bronzezeit . . . . . . . . . . . . . . . . . . . 5 I

4 Die relative Chronologie der Früheisenzeit im südöstlichen Siebenstromland . . . . . 65

4.I Zur absoluten Chronologie der Früheisenzeit . . . . . . . . . . . . . . 69

5 Sakische Nekropolen mit Fürstenkurganen als Zentrale Orte der Nomaden . . . . . . . 75

5.I Die Bauweise der Kurgane . . . . . . . . . . . . . . . . . . . . . 76

5.I.I Groß- und Kleinkurgane . . . . . . . . . . . . . . . . . . . 76

5.I.2 Abhänge der Kurgane . . . . . . . . . . . . . . . . . . . . . 85

5.I.3 Abdeckung der Kurgane . . . . . . . . . . . . . . . . . . . . . . . . . . 90

5.I.4 Aufbau der Kurgane: Funde und Befunde . . . . . . . . . . . . . 9I

5.I.5 Peripherie der Kurgane . . . . . . . . . . . . . . . . . . . $\mathrm{I04}$

5.I.5.I Peripheriekonstruktionen . . . . . . . . . . . . . . . . IO4

5.I.5.2 Sog. Prozessionswege . . . . . . . . . . . . . . . . . II8

5.I.5.3 Kreisgräben . . . . . . . . . . . . . . . . . . . . I22

5.I.5.4 Steinkreise . . . . . . . . . . . . . . . . . . . ${ }_{\mathrm{I} 26} 6$

5.I.5.5 Sonderfälle . . . . . . . . . . . . . . . . . . . . . 130

5.I.6 Viereckige Kurgane . . . . . . . . . . . . . . . . . . . . . 136

5.2 Die räumliche Struktur der Nekropolen . . . . . . . . . . . . . . . . I40

5.2.I Kettenmuster. . . . . . . . . . . . . . . . . . . . . . . I4I

5.2.2 Lage der größten Kurgane innerhalb einer Nekropole und
innerhalb einer Kette . . . . . . . . . . . . . . . . . . . . . I43

5.2.3 Lage der viereckigen Kurgane . . . . . . . . . . . . . . . . . . . . . $\quad$ I47

5.2.4 Lage der Kurgane mit Peripheriekonstruktionen . . . . . . . . . . . I48

5.2.5 Lage der Kurgane mit einem sog. Prozessionsweg . . . . . . . . . . . I49 
5.2.6 Lage der Kurgane mit einem Kreisgraben . . . . . . . . . . . . . $\quad$ I50

5.2.7 Lage der Kurgane mit einem Steinkreis . . . . . . . . . . . . . . $\quad$ I52

5.2.8 Lage der Kurgane mit Sonderfällen . . . . . . . . . . . . . . . . $\quad$ I53

5.3 Das Verhältnis der Nekropolen zueinander . . . . . . . . . . . . . . . . . $\quad$ I54

5.4 Der Bezug der Gräberfelder zum Gelände . . . . . . . . . . . . . . . 165

6 Siedlungen des Siebenstromlandes und ihre Zugehörigkeit zu den Zentralen Orten . . . . $\quad$ I74

7 Landschaftsklassifikation des Siebenstromlandes in der frühen Eisenzeit . . . . . . 188

8 Ergebnisse und Schlussfolgerungen . . . . . . . . . . . . . . . . . . . I9I

Resümee in russischer Sprache . . . . . . . . . . . . . . . . . . . . $20 \mathrm{I}$

Resümee in englischer Sprache . . . . . . . . . . . . . . . . . . . . 2I4

Resümee in kasachischer Sprache . . . . . . . . . . . . . . . . . . . 223

Teil II: Katalog der Fundorte, technische Graphiken, Listen und Verzeichnisse

Katalog der Fundorte . . . . . . . . . . . . . . . . . . . . . . . . .237

Die I4C-Datierungen. Graphische Darstellung der Datierungsergebnisse und Kalibration . . 439

Liste der untersuchten bronzezeitlichen Befunde . . . . . . . . . . . . . . . . 456

Verzeichnis der bronzezeitlichen Fundstellen mit Quellennachweis . . . . . . . . . . 465

Verzeichnis der früheisenzeitlichen Fundstellen mit Quellennachweis . . . . . . . . . 470

Liste der kartierten Fundorte in numerischer Ordnung . . . . . . . . . . . . . . 476

Liste der kartierten Fundorte in alphabetischer Ordnung c . . . . . . . . . . . . . 477

Literaturverzeichnis . . . . . . . . . . . . . . . . . . . . . . . . . . 478

Farbtafeln: Karten I-24 . . . . . . . . . . . . . . . . . . . . . . . . . . . . . 495

\section{Appendix Naturwissenschaftliche Untersuchungen von Jörg Faßbinder und Julia Gresky}

Magnetometerprospektion sakischer Kurgane: Das Gräberfeld Žoan Tobe mit einem Großkurgan und der Kurgan bei Kegen, Süd-Ost Kasachstan . . . . . . . . . . . 523 Von Jörg Faßbinder

Paläopathologische und anthropologische Untersuchungen an den menschlichen Skeletten

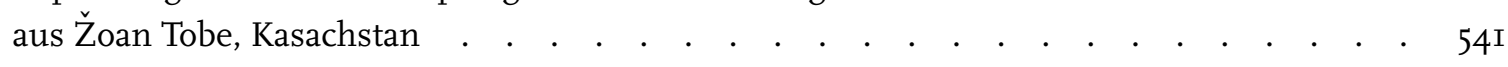
Von Julia Gresky 